Sultan Qaboos University Journal of Arts \& Social Sciences

جامعة السلطان قابوس مجلة الآداب والعلوم الاجتماعية

A Memetic Translation Assessment: The Case of Translating Polysystem Theory into Arabic

Hisham A. Jawad

Assistant Professor

Department of English Language and Literature

College of Arts and Social Sciences

Sultan Qaboos University 


\title{
A Memetic Translation Assessment: The Case of Translating Polysystem Theory into Arabic
}

\author{
Hisham A. Jawad
}

\section{Abstract:}

This study examines the underlying principles that trigger decisions in translating the polysystem translation theory into contemporary Arabic. The data comprises an English summary in Munday (2001) and its Arabic version. The methodology draws on the 'memes' notion and its application to translation. It consists in deconstructing the polysystem theory-meme so as to see why TT has been shaped the way it is. Two translation memes inform the mutation of the theory in Arab culture, i.e. Cognition which accounts for relevant memetic knowledge and expectations of target receptors, and Target calling for the supremacy of TL/TC. It is argued that the theory travels trans-nationally, carrying with it its history, but that history is never unsifted. It may be defied or re-interpreted pursuant to the memetic network in TC. The theory-meme subsumes an apparently cryptic meme of occupation in the political sense. This is evident through mapping the stylistic choices made by Even-Zohar in his article which suppress that sense. Therefore, TT serves as a vehicle whereby the theory-meme replicates itself in TC, having the embedded cryptic meme mutating and surfacing as explicit. It is the meme of occupation propagating in the sphere of Arab culture by general consensus.

Keywords: Memes, Translating style, Politics of translation, Rewriting

$$
\text { تقييم الترجمة وفق نظرية الميم: دراسة في الترجمة العربية لنظرية النظام التعددي هشام علي جواد }
$$

تتناول هذه الدراسة المبادئ الأساسية التي تحكم عملية اتخاذ القرارات المتعلقة بترجمة نظرية النقائة النظام التعددي إلى اللغة العربية.

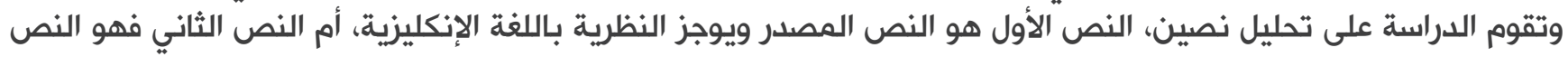

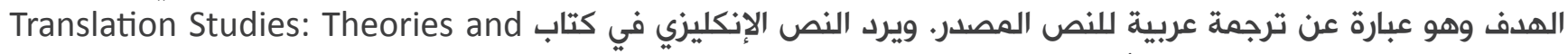
Applications (Munday 2001)

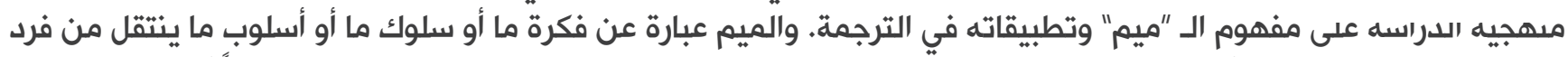

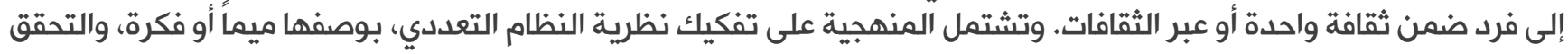

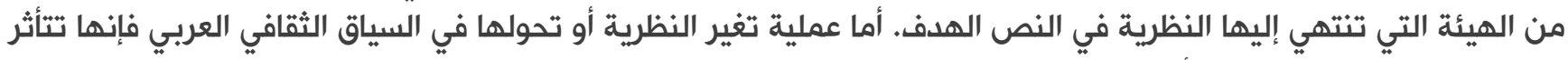

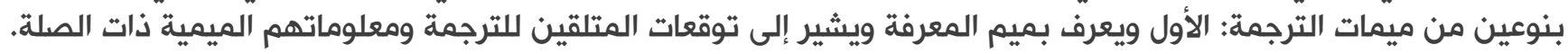

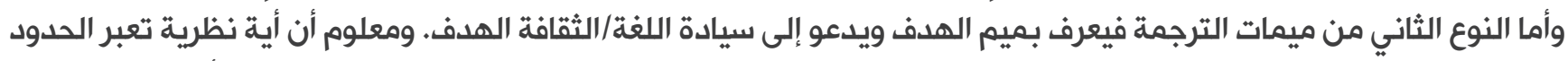

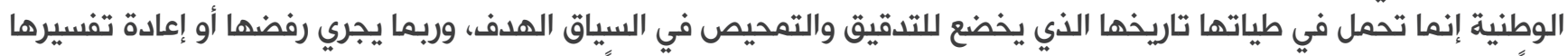

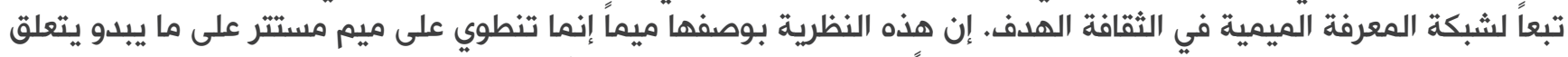

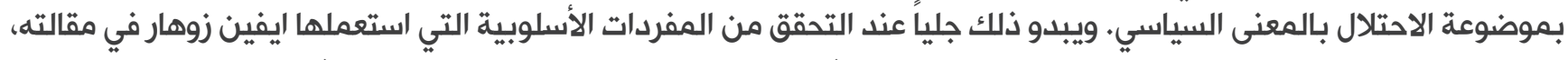

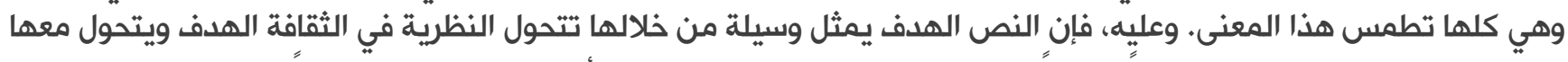
ميم الاحتلال المستتر ليصبح ظاهراً واضحاً في النص الهدف. ومما لا شك فيه أن الاحتلال بوصفه ميماً يشيع وينتشر في عالم الثقافة العربية. 
Translations give life, life both beyond that of the original text itself and beyond that of the original author. Translations propagate memes through both space and time. Chesterman (1997, p. 29)

\section{Introduction}

The study of theories of translation has always been widespread, but the study of translating theories of translation seems to be a rarity (Susam-sarajeva 2006). This article investigates the memes that inform the way the polysystem translation theory may be interpreted in the receiving Arab culture. The meme idea was first put forward by Dawkins (1976) in The Selfish Gene and applied to translation by Chesterman (1997) in his norms model. It relates to any idea or product that travels within the sphere of a certain culture and is accepted as a norm. The concept was intended by Dawkins to be the equivalent of a gene in the way the latter replicates itself throughout generations.

Within the theoretical framework suggested by Chesterman (1997), two translation memes have been singled out for the purpose of this study, viz. Target and Cognition. The former concerns the overriding target language and culture and the latter caters for target receptor expectations. The research questions of this study are: How can these two translation memes inform the way the polysystem theory is translated, and to what extent is the target text a replicate of the source text? But, first, a word about the concept of meme itself.

\section{The Concept of Meme}

Meme is a fundamental term in memetics and means a self-propagating idea. As mentioned above, the term was coined by the sociobiologist Richard Dawkins (1976) in his groundbreaking work The Selfish Gene and first introduced to translation studies by Chesterman (1997) and Vermeer (1997). Examples of memes are tunes, ideas, catchy phrases, fashions in dress, modes of architecture, food recipes, cultural commodities, etc. More specifically, memetics applies the principles of evolution by natural selection to beliefs. It has developed as a theory of culture specifically concerned with cultural transfer, cultural evolution and cultural similarity. The latter relates to both intra- and inter-cultural interactions and can be explained by three processes: biological evolution (heredity), individual learning (nonheredity), and cultural transmission (the memetic way). Memetics looks for parallels between genetic and cultural evolution.

The analogy with biology has been established where the cultural situation (memes) is parallel to the biological one (genes). The key biological principle here is the neo-Darwinian theory of selection and variation and the findings of genetics. Genes replicate through populations of organisms transferring copies or clones of themselves to subsequent generations; they maintain some distinctive features, i.e. identity, as they mutate and evolve. By the same token, memes propagate and evolve in the sphere of culture by selection and general consensus. They are transferred by all forms of communication throughout members of a given culture or cultures. They are everywhere surrounding us. They cannot be out of place or, as Dennett puts it (1995, p. 144), "no meme is an island".

Following Bjarneskans et al. (n.d.), Chesterman (2005, p. 24) lists five stages characterizing the life cycle of "successful" memes: transmission, i.e. knowledge is expressed; decoding, i.e. knowledge is received; infection, i.e. knowledge is restructured and processed; storage, where the meme becomes part of the host's memory; and survival, where the meme stands out as successful, i.e. knowledge is retained. Memetically transferred knowledge can be looked at as a pool of memes stored and developed in a memetic knowledge system:

Just as genes propagate themselves in the gene pool by leaping from body to body via sperms or eggs, so memes propagate themselves in the meme pool by leaping from brain to brain via a process which, in the broad sense, can be called imitation. If a scientist hears, or reads about, a 
good idea, he passes it on to his colleagues and students. He mentions it in his articles and his lectures. If the idea catches on, it can be said to propagate itself, spreading from brain to brain.

(Dawkins, [1976] 1989, p. 192)

Dawkins argues that memes should be seen as "living structures", both metaphorically and technically (p. 323). The concept of meme as a living structure has been experimentally explored by the brain scientist Delius, who provides a graphic picture of what the neuronal hardware of a meme might look like (cited in Dawkins, [1976] 1989, p. 323).

The meme for belief in life after death, Dawkins suggests, is realized physically millions of times over as a structure in the nervous systems of human beings, like the persisting idea of hell fire, due to its deep psychological impact. The two have become linked with the God meme as they reinforce each other's survival in the meme pool (p. 198).

Unlike genes, which can only survive for a few generations in the common gene pool, memes survive through contributing to the world's cultures by taking many varied forms, such as a word, idea, tune, poem, etc. Beethoven, Shakespeare or the Arab poet Al-Mutanabbi may not have their genes alive today. But, their meme complexes are still propagating themselves progressively. They include diverse idea-memes or entities capable of transferring from one brain to another. The meme of Beethoven's fifth symphony, Shakespeare's Hamlet, or the classical Arab poet Al-Mutanabbi's Diwan, is that essential basis of the work which is held by all brains that appreciate or understand it. In general, the sphere of memetics relates to cultural anthropology, semiotics and translation, among others. For that matter, a typology of memes has been suggested by scholars like Moritz (1990), who classifies them into four main categories: linguistic, visual, musical, and procedural/behavioural. A linguistic meme this study examines is Even-Zohar's polysystem theory: how it travels trans-culturally, what kind of mutation takes place in the Arab target culture and why.

Said, characterizing how theories travel, says:

Like people and schools of criticism, ideas and theories travel - from person to person, from situation to situation, from one period to another. [...] Having said that, however, one should go on to specify the kinds of movement that are possible, in order to ask whether by virtue of having moved from one place and time to another an idea or theory gains or loses in strength, and whether a theory in one historical period and national culture becomes altogether different for another period or situation. [...] Such movement into a new environment is never unimpeded. It necessarily involves processes of representation and institutionalization different from those at the point of origin. (1983, p. 226)

Thus, a theory-meme moving "into a new environment ... never unimpeded" undergoes a process of representation. This takes place typically via translation, whereby the theory-meme travels and propagates by mutation. An important study examining the impact of translation on the travel of ideas across linguistic-cultural borders is by Susam-sarajeva (2006). This discusses two cases where translation strategies crucially influenced the reception of imported schools of thought, i.e. structuralism and semiotics into Turkish and French feminism into English. Specifically, the researcher addresses the importation of both Roland Barthes's work into Turkish and Hélène Cixous's work into American English.

Susam-Sarajeva highlights the role translation plays in reshaping the images of Barthes and Cixous in the receiving systems. Presented as a structuralist and semiotician to the Turkish literary critical system, Barthes is merely viewed as an essayist. In the American context, Cixous's image shifts from a feminist theoretician to a writer. Simply, the migrating theories of structuralism and semiotics as well as French feminism faced certain resistance in their respective contexts.

Habitat of the Polysystem

Even-Zohar investigated extensively the 
beginnings of Hebrew literature in Israel. His work concentrated on the emergence and crystallization of native Hebrew culture in Palestine between 1882 and 1948. Now one of the most cited works on the history of modern Hebrew culture, ithas become a model for paradigmatic analysis of other emerging cultures.

The polysystem theory (Even-Zohar, 1978/2000) suggests a role for translated literature as a whole in the literary and historical systems of the target culture. These systems, including that of translated literature, enter into a continuous process of interaction conceptualized as a polysystem, which is defined by Shuttleworth and Cowie (1997, p.176) as "a heterogeneous, hierarchized conglomerate (or system) of systems which interact to bring about an ongoing, dynamic process of evolution within the polysystem as a whole".

The polysystem theory originated in a culture of immigrant communities and thus reflects the reality of Israeli colonization and occupation of Palestine. Immigrants flooded into Palestine bringing with them those literatures which were written in their native languages and then translated into Hebrew. A manifestation of those communities' rivalry for primacy in the hierarchy of the new society has to do with those translated literatures interacting as systems within the emerging multifarious polysystem. Yet this process of socio-cultural evolution has not gone unnoticed by the powers of the publishing industry and particularly the Israeli authorities.

Banham (1995) remarks that "until 1989, Israeli playwrights (whether writing in Arabic, Hebrew or English) were required to submit all scripts for prior approval by the Interior Ministry's Committee of Censorship of Plays and Films ... Any play judged to compromise Israeli state security could be closed without notice" (p. 185). Bergan (2000) reveals that since 1967 when Israel occupied the West Bank and Gaza, Israeli censorship has been aggressive, banning a list of over 1.600 book titles, George Orwell's 1984 being only one. Some 600 additional titles were included later. The list includes every work that aroused Palestinian national feelings. The word Palestine in a title is enough.

Another aspect of government practice concerns the official attitude towards university professors and the intelligentsia. Davidson (2006) notices that those who publicly criticize the occupation are subjected to isolation and the ruin of their careers. Any verbal references to the occupation is never condoned. Indeed, for a long time, the Israelis refused to even entertain the word occupation for what they were doing. As the Israeli writer David Grossman explains:

There was a whole machinery of fabricating names for the situation, there was a whole narrative that in a way used words not to describe reality but rather to camouflage it, to protect us the Israelis from the harshness of what we are doing. This is what the Israeli Lawyer Leah Tsemel calls the "laundering of language." In Hebrew "occupation" became "release" or "salvation," while "colonizing" became "peaceful settlement" and "killing" became "targeting." Orwell would have recognized this use of "political language" without much trouble. (Cited in: Davidson, 2006, p. 260)

Now, Even-Zohar's article can be viewed within this socio-political context, and it might be the case that the author opted not to over-use the word occupy, choosing instead assume. One could object to this reading on the basis of authorial stylistic preference. However, the argument here is never gratuitous, given that Even-Zohar himself is an opponent of Israeli settlement policies (Cf. Even-Zohar, 1998). The idea of occupation, the reality of occupation, has been going on in the Israeli mind for over half a century. But it is hidden, curbed or at best only hinted at. At the discourse level, it can be seen as embedded within the theory-meme of polysystem, which mirrors how different literary and historical systems strive to occupy the primary position therein.

The relation between a theory and its original social context has been widely discussed. Miller argues that:

Literary theory [...] in spite of its high degree of 
apodictic generalization, is tied, perhaps even inextricably tied, to the language and culture of its country of origin. Though theory might seem to be as impersonal and universal as any technological innovation, in fact it grows from one particular place, time, culture, and language. It remains tied to that place and language. Theory, when it is translated or transported, when it crosses a border, comes bringing the culture of its originator with it. (Miller, 1996, p. 210; emphasis added) But a travelling theory is never unfiltered. It may be rejected, challenged or re-interpreted pursuant to the ideology of the target culture.

\section{The Data and Methodology}

In order to see how the polysystem theory can be interpreted, a synopsized version (Box 1) in Munday (2001) together with its Arabic 'literal' translation (Box 2) produced and published in Munday (2010) by the present author were examined. Since an Arabic translation of EvenZohar's article was inaccessible, Munday's summary was considered as a ST for translation analysis purposes. The methodology involves mapping the TT onto the ST so as to identify those aspects and choices where the two texts diverge. It is based on the model of translation memes and strategies suggested by Chesterman (1997). Two translation (super) memes will be investigated: Target and Cognition. The former sees the target language/culture as superior to the source language/culture, whilst the latter considers the expectations of receptors highly important so far as they can make right inferences about the communicative clues provided by the translation. These two memes have ideological and cognitive implications, respectively, and set the ground on which the translation strategy is founded.

As to the translation strategies, Chesterman classifies them into "reduction strategies", which change or reduce the message in some way and "achievement strategies", which attempt to preserve the message but change the means, such as the use of paraphrase, approximation, restructuring, mime etc. He defines "strategy" as "a kind ot process, a way ot doing something" (p. 88), and states that "strategies are forms of explicitly textual manipulation" (p. 89). This is, in general, the theoretical framework adopted in the present study.

Box 1 - ST (Munday, 2001, pp. 109-10)

Polysystem theory was developed in the 1970s by the Israeli scholar Itamar borrowing ideas from the Russian Formalists of the 1920s, who had worked on literary historiography.

$$
\text { [...] }
$$

The hierarchy referred to is the positioning and interaction at a given historical moment of the different strata of the polysystem. If the highest position is occupied by an innovative literary type, then the lower strata are likely to be occupied by increasingly conservative types. On the other hand, if the conservative forms are at the top, innovation and renewal are likely to come from the lower strata. Otherwise a period of stagnation occurs [...]. This 'dynamic process of evolution' is vital to the polysystem, indicating that the relations between innovatory and conservative systems are in a constant state of flux and competition. Because of this flux, the position of translated literature is not fixed either. It may occupy a primary or a secondary position in the polysystem [...]. EvenZohar gives three major cases when translated literature occupies the primary position [...].

If translated literature assumes a secondary position, then it represents a peripheral system within the polysystem. It has no major influence over the central system and even becomes a conservative element, preserving conventional forms and conforming to the literary norms of the target system. Even-Zohar points out that this secondary position is the 'normal' one for translated literatures. However, translated literature itself is stratified. Some translated literature may be secondary while others, translated from major source literatures, are primary. An example Even-Zohar gives is of 
the Hebrew literary polysystem published between the two world wars, when translations from Russian were primary but translations from English, German and Polish were secondary.

Even-Zohar suggests that the position occupied by translated literature in the polysystem conditions the translation strategy. If it is primary, translators do not feel constrained to follow target literature models and are more prepared to break conventions, They thus often produce a TT that is a close match in terms of adequacy, reproducing the textual relations of the ST This in itself may then lead to new SL models. On the other hand, if translated literature is secondary, translators tend to use existing target-culture models for the TT and produce more 'non-adequate' translations.

Box 2 - TT (Munday, 2010, pp. 153-55)

نشأت نظرية النظام التعددي في سبعينات القرن الماضي على القائى

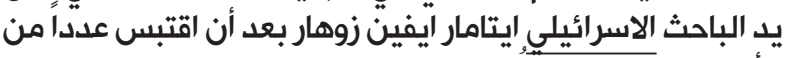

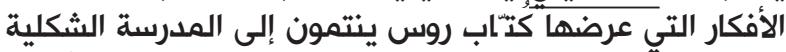
في عشرينات القرن الماضي تناولوا فيها موضون التى التاريخ الأدبي. $[\ldots]$

وتمثل الهرمية المشار إليها ترتيب المستويات المختلفة للنظام

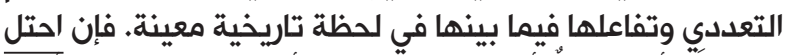

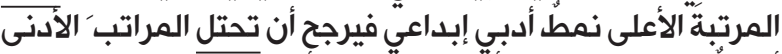

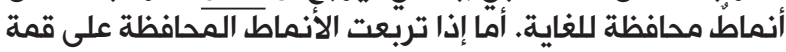

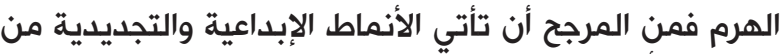

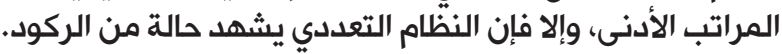

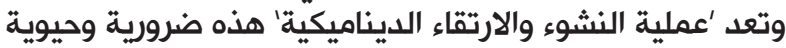

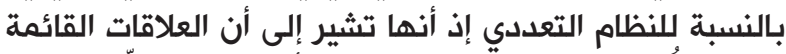

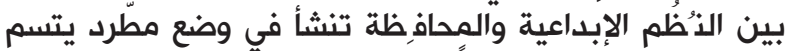

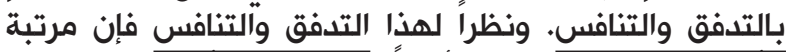

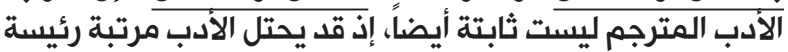

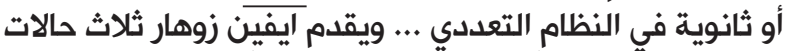
رئيسة يحتلّ فيها الأدب المترجم المرتبة الأونية الأولى ...

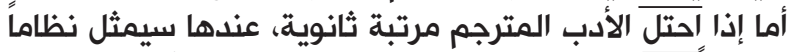

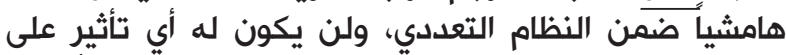

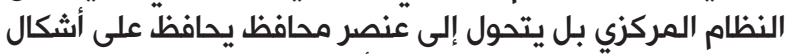

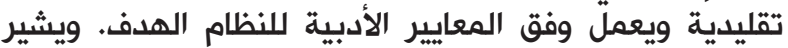

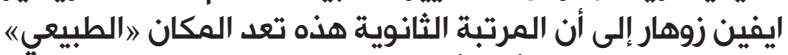

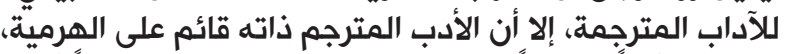

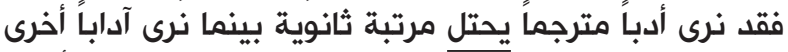

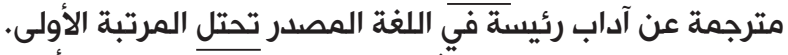
ويستشهد ايفين زوهار بمثثال يتعلق بالنظام التعام التعددي الأدبي الأبي

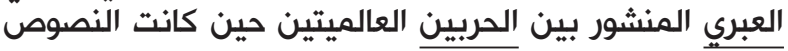

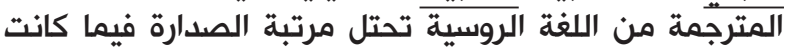
النصوص المترجمة من اللغات الإنكليزية والألمانية والبولندية فية المانية
تحتل مرتبة متدنية.

ويرى ايفين زوهار أن المرتبة التي يحتلها الأدب المترجم في تئدئ

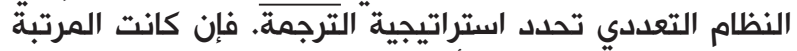

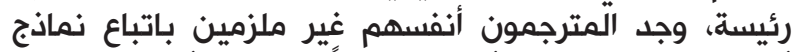

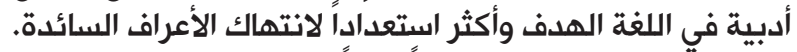

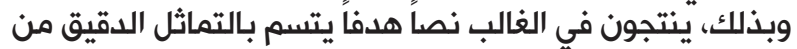

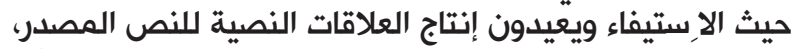

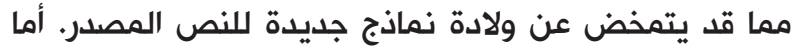

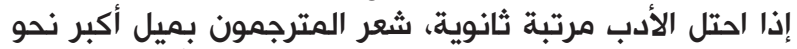

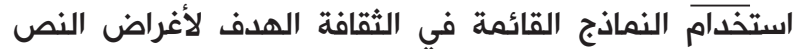
الهدف وإنتاج ترجمات 》غير وآفية) النية

\section{Source Text Focus}

The ST is an extract of a section on the polysystem theory in Jeremy Munday's book Introducing Translation Studies: Theories and Applications published in 2001. The section itself is a brief account of the theory put forward by Even-Zohar (1978/2000), suggesting a role for the translated literature as a whole in the literary and historical systems of the target culture. These systems, including that of translated literature, enter into a continuous process of interaction conceptualized as a polysystem which is defined by Shuttleworth and Cowie (1997, p. 176) as "a heterogeneous, hierarchized conglomerate (or system) of systems which interact to bring about an ongoing, dynamic process of evolution within the polysystem as a whole" (cited in Munday, 2001, p. 109).

The ST consists of a total of 373 words. I have chosen one text focus which has to do with the central notion of interaction between different systems to assume different positions in the hierarchy of polysystem and how this interaction is lexicalized. Put another way, it is about 'occupying a position', i.e. the key element in the author's argument. The excerpt includes the following associations with position:

- If the highest position is occupied by

- to be occupied by

- translated literature occupies the primary position

-translated literature assumes a secondary position

- Some translated literature may be secondary while others, ..., are primary 
- translations from Russian were primary but translations from English, German and Polish were secondary

- the position occupied by translated literature - if translated literature is secondary

The ST has 44\% (4/9) of the collocations with position including (derivations of) the word occupy.

Zooming in on the very notion as elaborated by Even-Zohar (1978) in his paper The Position of Translated Literature within the Literary Polysystem, one can mark a quite carefully selected pattern of words associated with position:

- win the central position

- one of which occupies the top position

- positions assumed by various types

- the top position is maintained by a literary type - the top position is maintained by an ossified type

- the position of the translated literature in this constellation

- it maintains no unchanging position

- to say that translated literature maintains a primary position

- I point out that these literatures may rise to a central position in a way analogous to the way this is done by secondary systems within a certain polysystem

- some literatures take peripheral positions

- translated literature may assume a primary position

- translated literature may consequently assume a primary position

- translated literature maintains a secondary position

- one section of translated literature may assume a primary position, another may remain secondary - a major source literature which is likely to assume a primary position

- literature translated from the Russian assumed an unmistakable primary position

- works translated from English, German, ... assumed an obviously secondary one

- the chances of translated literature to assume a certain position
- work ... indicates that the "normal" position assumed by translated literature tends to be the secondary one

- have caused French translated literature to assume an extremely secondary position

- what bearings may the position taken by translated literature have on translational norms

- the position assumed by the translated literature

- when it takes a primary position

- when it assumes a primary position

- naturally, translated literature, when it occupies a secondary position

In his article which runs 3549 words, the frequency of occurrences with position are: occupy (2), take (3), maintain (5), and assume (12). This pattern is formally distinct from that found in the summary as Even-Zohar uses occupy twice (9\%) compared to four times (44\%). Now, legitimate questions may be raised here: why does the word occupy appear merely two times in the original work? What was likely the constraint on that? Was it arbitrary? Was it a feature attributed to the author's style, or possibly conditioned by the socio-political factors which had been prevalent since 1967, the year when Israel occupied Palestinian and Arab territories? How do the socio- or geo-political factors impact the way writers write?

The answers to these questions will have to take into account the origins of the polysystem theory, social context, and historical circumstances that surrounded the emerging Israel.

\section{Discussion and Conclusion}

This work has had as its goal to deconstruct the theory-meme in an attempt to see why the TT has been shaped the way it is. Two translation memes have informed the strategy of translating the ST: Cognition and Target.

In the sphere of target culture, Arab receptors have acquired in their memetic knowledge pool the meme of Israeli occupation being a major political concern. While it is suppressed on the Israeli side, the meme is quite explicit and active, dominating contemporary Arab socio-political thought. One 
of the textual resources utilized to uncover this political meme in translation is lexical repetition. By replacing the lexical choices associated with the word position, i.e. assume, maintain, be, etc., the network of synonymy and cross-referencing, with other choices based on the recurrence of occupy, the stylistic configuration of the TT seems to partly echo the socio-cultural grounds on which the theory was built in the first place. Now, what the ST fell short of voicing explicitly is done in the TT which exhibits how different systems interact to occupy a specific position in the polysystem. This interpretation may not be captured by ordinary readers in the target culture. However, the expectations of receptors, in general, are accounted for and relevant clues provided for correct inferences (Gutt, 1991). It may be safe to argue, though, that only a critical reader is able and willing to successfully decode the implicit meaning encoded in the translation. It is this critical reader who is disposed to hear the second voice between the lines. This type of reader will find the meaning potential relevant to his expectation as it matches a paramount themememe prevalent in the target culture, i.e. Israeli occupation.

This leads us to the second translation meme, Target, which assumes that everything related to the target language/culture is overriding and, thus, sees a translation in terms of acceptability, naturalness, fluency, etc. Favourable in Arabic, repetition serves an effective device for building text cohesion and, thus, is more welcome than in English (Baker, 1992). The strategy of translating the summary largely utilizes lexical repetition, being a dominant feature of explicitness in Arabic discourse.

It has been argued that, as a meme, the polysystem theory travels trans-nationally carrying with it its history, but that history is never unsifted. It may be resisted, challenged, or re-interpreted pursuant to the memetic network in the target culture. The theory-meme subsumes an apparently cryptic meme of position-occupying, but this meme is never explicitly lexicalized. Therefore, the translation works as a vehicle whereby the theory-meme replicates in the target culture having the cryptic meme mutating and surfacing as an explicit meme in the target text. It is the meme of occupation propagating and evolving in the sphere of Arab culture by general consensus. Venuti claims that "all translations inevitably perform a work of domestication" (1998, p. 5). This involves manipulating the traveling discourse for local purposes. The target culture, as such, deals with the translations on its own ground rather than that of the original culture.

This study has attempted to provide an insight into the polysystem theory through translation. It suggests a fresh reading of the model and its origins, a reading which would decipher the meme of occupation.

\section{References}

Baker, M, 1992, In Other Words: A Coursebook on Translation. London \& New York: Routledge.

Banham, M, 1995, The Cambridge guide to theatre. Cambridge: Cambridge University Press.

Bergan, E, 2000, Libraries in the West Bank and Gaza: Obstacles and possibilities. In: The Proceedings of the 66th IFLA Council and General Conference Jerusalem, pp. 13-18 August, Israel.

Bjarneskans, H., B. Grønnevik and A. Sandberg. (nd). The Lifecycle of Memes. http://www.aleph. se/Trans/Cultural/Memetics/memecycle.html Accessed on 22.03.2011.

Chesterman, A, 1997, Memes of Translation: The Spread of Ideas in Translation Theory. Amsterdam \& Philadelphia: Benjamins.

Chesterman, A, 2005, The Memetics of Knowledge. In: H. V. Dam, J. Engberg, \& H. Gerzymisch-Arbogast (Eds.). Knowledge Systems and Translation, pp. 17-30. Berlin: Mouton de Gruyter.

Davidson, L, 2006, Orwell and Kafka in IsraelPalestine. In: S. E. Bronner \& M. Thompson (Eds.). The Logos Reader: Rational Radicalism and the Future of Politics, pp. 253-266. Kentucky: The University Press of Kentucky.

Dawkins, R, 1976, The Selfish Gene. Oxford: Oxford University Press. (New edition 1989). 
Delius, J, 1989, Of Mind Memes and Brain Bugs: a Natural History of Culture. In: W. A. Koch (Ed.). The Nature of Culture, pp. 26-79. Bochum: Studienlag Brockmeyer.

Dennett, D, 1995, Darwin's Dangerous Idea: Evolution and the Meanings of Life. London: Penguin.

van Dijk, T. A, 2002, Political Discourse and Political Cognition. In: P. Chilton \&

C. Schäffner (Eds.). Politics as text and talk: Analytical Approaches to Political Discourse, pp. 203-237. Amsterdam \& Philadelphia: Benjamins. Even-Zohar, I, 1978/2000, The Position of Translated Literature within the Literary Polysystem. In: L. Venuti (Ed.). The Translation Studies Reader, pp. 192-197. London: Routledge. Even-Zohar, I, 1998, Some Replies to Lambert and Pym. Target, 10 (2), 363-369.

Gutt, E, 1991, Translation and Relevance: Cognition and context. Oxford: Basil Blackwell.

Miller, H. J, 1996, Border Crossings, Translating Theory: Ruth. In: B. Sanford \& W. Iser (Eds.). The Translatability of Cultures: Figurations of the Space Between, pp. 207-223. Stanford: Stanford University Press.

Moritz, E, 1990, Memetic Science: I - General Introduction. Journal of Ideas 1, 1-23.

Munday, J, 2001, Introducing Translation Studies: Theories and Applications. London \& New York: Routledge.

Munday, J, 2001, Introducing Translation Studies: Theories and Applications. H. Jawad (Trans.). 2010. Abu Dhabi: Abu Dhabi Culture and Heritage. Said, E, 1983, The World, the Text and the Critic. Cambridge \& Massachusetts: Harvard University Press.

Shuttleworth, M. \& M. Cowie, 1997, Dictionary of Translation Studies. Manchester: St. Jerome.

Susam-Sarajeva, Ş, 2006, Theories on the Move: Translation's Role in the Travels of Literary Theories. Amsterdam \& New York: Rodopi.

Venuti, L, 1998, The Scandals of Translation: Towards an Ethics of Difference. London \& New York: Routledge.

Vermeer, H. J, 1997, Translation and the 'Meme'.
Target 9 (1), 155-166. 